\title{
Defects in Base Excision Repair Sensitize Cells to Manganese in S. cerevisiae
}

\author{
Adrienne P. Stephenson, Tryphon K. Mazu, Jana S. Miles, Miles D. Freeman, \\ R. Renee Reams, and Hernan Flores-Rozas
}

Florida A\&M University, College of Pharmacy \& Pharmaceutical Sciences, 1520 Martin Luther King Boulevard, Dyson Building Room 221, Tallahassee, FL 32307, USA

Correspondence should be addressed to Hernan Flores-Rozas; hernan.floresrozas@famu.edu

Received 1 July 2013; Accepted 10 September 2013

Academic Editor: Shivani Soni

Copyright (c) 2013 Adrienne P. Stephenson et al. This is an open access article distributed under the Creative Commons Attribution License, which permits unrestricted use, distribution, and reproduction in any medium, provided the original work is properly cited.

\begin{abstract}
Manganese (Mn) is essential for normal physiologic functioning; therefore, deficiencies and excess intake of manganese can result in disease. In humans, prolonged exposure to manganese causes neurotoxicity characterized by Parkinson-like symptoms. $\mathrm{Mn}^{2+}$ has been shown to mediate DNA damage possibly through the generation of reactive oxygen species. In a recent publication, we showed that $\mathrm{Mn}$ induced oxidative DNA damage and caused lesions in thymines. This study further investigates the mechanisms by which cells process $\mathrm{Mn}^{2+}$-mediated DNA damage using the yeast $S$. cerevisiae. The strains most sensitive to $\mathrm{Mn}^{2+}$ were those defective in base excision repair, glutathione synthesis, and superoxide dismutase mutants. $\mathrm{Mn}^{2+}$ caused a dose-dependent increase in the accumulation of mutations using the CAN1 and lys2-10A mutator assays. The spectrum of CAN1 mutants indicates that exposure to $\mathrm{Mn}$ results in accumulation of base substitutions and frameshift mutations. The sensitivity of cells to $\mathrm{Mn}^{2+}$ as well as its mutagenic effect was reduced by $\mathrm{N}$-acetylcysteine, glutathione, and $\mathrm{Mg}^{2+}$. These data suggest that $\mathrm{Mn}^{2+}$ causes oxidative DNA damage that requires base excision repair for processing and that $\mathrm{Mn}$ interferes with polymerase fidelity. The status of base excision repair may provide a biomarker for the sensitivity of individuals to manganese.
\end{abstract}

\section{Introduction}

Manganese $(\mathrm{Mn})$ is a trace element that has been extensively documented for its varied role in the body's homeostasis. As an essential nutrient, $\mathrm{Mn}$ is required for the normal function and development of the brain [1], metabolism of proteins, lipids, and carbohydrates [2-4], and also as a functional unit for many enzymes [3-5]. Therefore, deficiencies that affect fetal development [6] and excess Mn (environmental exposure and/or elevated dietary Mn [7]), can result in disorders and disease.

There is increasing concern for the use of organic compounds containing manganese in industrial settings. In recent years, methylcyclopentadienyl manganese tricarbonyl (MMT) gained approval for use in the United States as an octane enhancing fuel additive used in unleaded automotive gasoline. Exposure to Mn has also increased through occupation and environmental settings. This includes agrochemicals such as the fungicides, maneb and mancozeb, and pesticides in the agriculture and forest industries [8] as well as in the case of miners, smelters, welders, and workers in battery factories [9]. The increase in atmospheric levels could result in potential health risks.

At elevated levels of exposure, Mn has been shown to cause manganism, which is an excess of manganese in the basal ganglia [10]. Manganism is characterized by neurological symptoms resembling the dystonic movement associated with Parkinson's disease (PD) [11-13] and therefore is a risk factor for idiopathic Parkinson's disease (IPD). Although Mn has been studied for years, the mechanism by which it causes neuronal damage is not well understood. Studies suggest that neurotoxicity is not caused by a single factor but that it appears to be regulated by a number of factors including apoptosis, oxidative injury, DNA damage, mitochondrial dysfunction, and neuroinflammation [14-18].

The mutagenicity of $\mathrm{Mn}$ has been extensively documented [19]. Mn has been shown to cause damage to DNA in multiple cell-based assays $[18,20]$, to interfere with the 
fidelity of DNA replication [21], to activate the DNA damage response [22], to induce mutations in T4 phage replication [23] and yeast mitochondria replication [24, 25], and, inhibit repair factor PARP in human cells [26], albeit not scoring as a direct mutagen in the Ames test [27]. Despite its mutagenicity, Mn is not classified as a carcinogen in humans. The reasons for this discrepancy are still not clear.

Research on manganese toxicity has increased in recent years. However, the mechanisms underlying its multiple toxicities (neurotoxicity, genotoxicity, mutagenicity, etc.) [19] remain a mystery. It is possible that redundant mechanisms of DNA repair exist which are effective to handle the levels of Mn to which cells are exposed.

The goal of the current study is to gain insight into the pathways that are involved in DNA damage/repair that contribute to protecting cells from the toxicity of manganese (Mn). The yeast S. cerevisiae was utilized as a model system to study the genotoxic effects of Mn. Yeast has proven to be an excellent eukaryotic model for studying metal, and players identified through genetic studies virtually all have homologues in humans. In our study, we use two well-established mutator assays. The CAN1 assay was used to measure the induction of forward mutations, and the lys2-10A reversion assay was used to assess replication fidelity. Furthermore, this study examines the protective effects of the antioxidants $\mathrm{N}$-acetylcysteine and glutathione, as well as $\mathrm{Mg}^{2+}$ on $\mathrm{Mn}$ induced toxicity and mutagenesis.

\section{Materials and Methods}

2.1. General Genetic Methods and Strains. Yeast extract/ peptone/dextrose (YPD, $1 \%$ yeast extract, 2\% peptone, $2 \%$ dextrose, $2 \%$ agar) and synthetic complete (SC, $0.67 \%$ yeast nitrogen base without amino acid, $0.087 \%$ amino acid mixture, $2 \%$ dextrose, $2 \%$ agar) media or the corresponding drop-out media were as described in [28, 29]. Homozygous haploid deletion strains library (Parental strain BY4741: MATa his $3 \Delta 1$ leu2 $\Delta 0$ met15 $\Delta 0$ ura3 $\Delta 0$ ) was obtained from Thermo Scientific (Pittsburgh, PA, USA).

2.2. Chemicals. Manganese chloride tetrahydrate $\left(\mathrm{MnCl}_{2}\right.$ $4 \mathrm{H}_{2} \mathrm{O}$ ), $\mathrm{N}$-acetylcysteine (NAC), glutathione (GSH), canavanine, and yeast media were purchased from Sigma-Aldrich (St. Louis, MO, USA).

2.3. Sensitivity of Strains to $\mathrm{Mn}^{2+}$ and Effect of NAC and GSH. The concentration of $\mathrm{Mn}^{2+}$ for strain exposure was determined experimentally using the wild type parental strain, BY4741. Briefly, single colonies were grown for $16 \mathrm{~h}$ on YPD with or without $\mathrm{Mn}^{2+}$ at $30^{\circ} \mathrm{C}$ with shaking. Cells were then washed with and resuspended in sterile water. Serial dilutions were spotted onto YPD and plates were incubated at $30^{\circ} \mathrm{C}$. Cell growth was monitored daily and sensitivity was scored after 3 days. Colonies were counted and survival (in percentage) was calculated relative to the untreated control. Each strain was tested using at least five independent colonies for each $\mathrm{Mn}^{2+}$ concentration tested. To determine the effect of thiol-based antioxidants, cells were cotreated with $\mathrm{Mn}^{2+}$ and $\mathrm{N}$-acetylcysteine (NAC) or
TABLE 1: Strains used in this study.

\begin{tabular}{|c|c|c|}
\hline Gene & ORF & Function \\
\hline HSP104 & YLL026W & Protein disaggregase \\
\hline RAD2 & YGR258C & $\begin{array}{l}\text { Nucleotide excision repair } \\
\text { endonuclease }\end{array}$ \\
\hline RAD52 & YML032C & Homologous recombination \\
\hline SOD2 & YHR008C & Mitochondrial superoxide dismutase \\
\hline RAD18 & YCR066W & Postreplication repair \\
\hline CTA1 & YDR256C & Catalase activity \\
\hline SOD1 & YJR104C & Superoxide dismutase activity \\
\hline$M L H 1$ & YMR167W & Mismatch repair \\
\hline GSH2 & YOL049W & Glutathione synthetase activity \\
\hline GSH1 & YJL101C & Glutamate-cysteine ligase activity \\
\hline$A P N 1$ & YKL114C & Base excision repair \\
\hline UBC13 & YDR092W & DNA postreplication repair \\
\hline RAD27 & YKL113C & Base excision repair, DNA replication \\
\hline RAD30 & YDR419W & Bypass synthesis DNA polymerase \\
\hline NTG1 & YAL015C & Base excision repair \\
\hline
\end{tabular}

Wild type: strain BY4741 (MATa his $3 \Delta 1$ leu2 $\Delta 0$ met15 $\Delta 0$ ura $3 \Delta 0$ ). RDKY3590 (MATa, ura3-52, leu2D1, trp1D63, hom3-10; lys210A).

glutathione (GSH) at the concentrations indicated in each figure. Survival was calculated as described above.

2.4. Mutation Analysis. The effect of $\mathrm{Mn}^{2+}$ on the accumulation of mutations was assessed by the CAN1 forward mutation assay and the lys2-10A mutation reversion as previously described [30, 31]. Mutation rates were determined by fluctuation analysis using at least five independent colonies [29, 32]. Each fluctuation test was repeated at least three times. The CAN1 forward mutation assay relies on the introduction of mutations on the CAN1 gene which encodes the arginine permease allowing mutant cells to grow on plates containing the toxic arginine analog, canavanine. The lys2-10A reversion assay is based on the restoration of the open-reading frame in a mononucleotide run of 10 adenines within the lys 2 allele of strain RDKY3590 (Table 1), allowing mutant cells to grow on plates lacking lysine.

2.5. DNA Sequence Analysis. Spectrum analysis was carried out by selecting mutants $\left(\mathrm{Can}^{r}\right)$ on selective minimum media drop-out plates containing canavanine [29]. Chromosomal DNA was isolated from the mutants and the relevant region of CAN1 was amplified by PCR and sequenced [30]. Sequence was carried out at MCLAB (San Francisco, CA, USA). Sequence analysis was carried out using Sequencher (Gene Codes, Ann Arbor, MI, USA).

2.6. Statistical Analysis. Data analysis and graphing were performed using the GraphPad Prism 4 software package. Specific analysis for each experiment is indicated in each figure legend. In most cases, the mean of at least three experiments is plotted together with the standard deviation. Differences between mean values and multiple groups were 


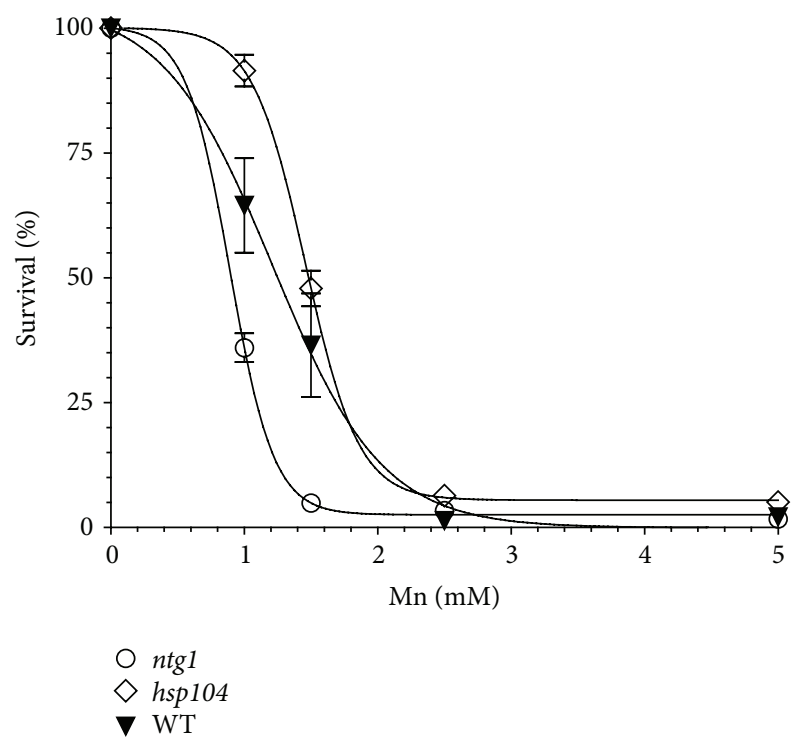

FIGURE 1: Dose-dependent response of selected yeast strains to $\mathrm{Mn}^{2+}$. Wild-type parental strain (BY4741) was tested for growth on media after exposure to $0,0.5,1.5,2.5$, and $5 \mathrm{mM} \mathrm{Mn}^{2+}$ as indicated in Materials and Methods. Survival was determined by counting the number of colonies in the respective dilutions and calculated based on the growth of cells not exposed to $\mathrm{Mn}^{2+}$ (100\% survival). Mutant strains $n t g 1$ and $h s p 104$ that display increased and reduced sensitivity to $\mathrm{Mn}^{2+}$, respectively, are shown for comparison. The curve was fitted by nonlinear Sigmoidal dose response (variable slope).

analyzed by one-way analysis of variance (ANOVA). Statistical significance was set at $P<0.05$.

\section{Results}

3.1. Sensitivity of S. cerevisiae Strains to $\mathrm{Mn}^{2+}$. To perform a comparative analysis of the differential sensitivity of yeast strains, we first determined the dose of $\mathrm{Mn}^{2+}$ appropriate for the study. We initially used the wild type strain to determine the range of $\mathrm{Mn}^{2+}$ concentrations and found that there was a linear response in a narrow window between 1 and $2.5 \mathrm{mM}$ (Figure 1), with the higher concentration resulting in viability below 5\%, which did not significantly increase at higher concentrations of $\mathrm{Mn}^{2+}$. All selected strains were then exposed to this range of $\mathrm{Mn}^{2+}$ concentrations. Figure 1 shows a comparison between the wild type strain, the disaggregase hsp104 mutant, which displays higher tolerance to $\mathrm{Mn}^{2+}$, and the base excision repair ntgl mutant, which is more sensitive. $\mathrm{Mn}^{2+}$ at $1.5 \mathrm{mM}$ was determined to be the optimal concentration for the strain comparison (Figure 1). At this concentration, wild-type cells displayed approximately $40 \%$ survival and sensitive strains showed higher sensitivity relative to the wild-type strain (Figure 1).

Based on published evidence and a recent report by Stephenson et al. [18], we selected several mutant strains that play a role in the mutagenicity avoidance and may be involved in processing $\mathrm{Mn}^{2+}$-induced DNA damage (Table 1). These mutants strains include those defective in nucleotide excision repair ( $\mathrm{rad} 2$ ), postreplication repair ( $\mathrm{rad} 18, \mathrm{rad} 27 \mathrm{a}$, and $u b c 13$ ), base excision repair (apn1, rad27, and ntg1), homologous recombination ( rad52), DNA mismatch repair $(m l h 1)$, and DNA damage bypass ( $r a d 30)$, glutathione synthesis $(g \operatorname{sh} 1$ and $g s h 2)$, oxidative stress ( $\operatorname{sod} 1, \operatorname{sod} 2$, and $\operatorname{cta} 1)$, and protein disaggregation (hsp104). Quantitative analysis involved exposing the cells to $\mathrm{Mn}^{2+}$ as described under Materials and Methods and spotting serial dilutions onto nonselective media YPD for colony counting. As observed in Figure 2(a), no significant difference was observed on the growth rate of each strain in the absence of $\mathrm{Mn}^{2+}$ (control panel), except for slow growing strain $n$ tg1. However, upon treatment with $\mathrm{Mn}^{2+}$, the strains displayed differential sensitivity to the metal. All strains tested were sensitive to $\mathrm{Mn}^{2+}$ however, only the hsp104 mutant displayed less sensitivity than the wild type (48\% versus $37 \%$; Figure $2(\mathrm{~b})$, black bar). No significant difference between $\mathrm{rad} 2(33.2 \%$ survival) and the wild type was observed, suggesting that $\mathrm{Mn}^{2+}$-induced DNA damage does not result in bulky adducts that require NER for processing. Similarly, no significant difference between rad52 (31\% survival) and the wild type indicates that no significant DNA damage is processed to DNA double-strand breaks that require homologous recombination for repair. Interestingly, the oxidative stress mutants sod $1, \operatorname{sod} 2$, and $\operatorname{cta} 1,(15 \%, 21 \%$, and $17 \%$ survival, resp.) were approximately 2 -fold more sensitive than wild type and the glutathione synthesis mutants $g s h 1$ and $g s h 2$ (10.6\% and $13.6 \%$ survival, resp.) were 3 -fold more sensitive. Mismatch repair mutants $m l h 1$ displayed $14.5 \%$ survival, suggesting that $\mathrm{Mn}^{2+}$ induces an increased load of mismatches that cannot be repaired. More striking was the sensitivity of the base excision repair mutants apn1, rad27, and $n t g 1,(9.5 \%, 9.2 \%$, and $4.9 \%$ survival), which were over 4-fold more sensitive to $\mathrm{Mn}^{2+}$ than wild type (Figure 2(b)), with ntg1 being the most sensitive (7.5fold). In addition, $u b c 13$ and rad30 mutants were also highly sensitive ( $\sim 4$-fold higher than wild type), further suggesting the generation of $\mathrm{Mn}^{2+}$-induced DNA damage.

3.2. Attenuation of the Sensitivity to $\mathrm{Mn}^{2+}$ by Exogenous Antioxidants. Considering that oxidative stress mutants sod1, sod2, and ctal and glutathione synthesis mutants gsh1 and ghs2 displayed higher sensitivity to $\mathrm{Mn}^{2+}$ than wild-type, we tested if antioxidants would protect from $\mathrm{Mn}^{2+}$-induced cytotoxicity. As shown in Figure 3, exogenously added NAC and GSH protected both the wild-type and the hypersensitive strain $u b c 13$. The concentration of $\mathrm{Mn}^{2+}$ was increased to $2 \mathrm{mM}$ to effectively determine the protective effects of the antioxidants on wild-type cells, resulting in $20 \%$ survival. Cotreatment of wild-type cells with $2 \mathrm{mM} \mathrm{Mn}^{2+}$ and $20 \mathrm{mM}$ NAC increased the survival to $42 \%$, a 2 -fold increase (Figure 3). Similarly, cotreatment with $10 \mathrm{mM} \mathrm{GSH}$ increased survival to $44 \%$, a 2 -fold increase (Figure 3 ). To test the protective effect of NAC and GSH on a sensitive strain, we selected $u b c 13$, which displayed $9 \%$ survival when treated with $1.5 \mathrm{mM}$ $\mathrm{Mn}^{2+}$. Cotreatment with $20 \mathrm{mM}$ NAC and $1.5 \mathrm{mM} \mathrm{Mn}^{2+}$ increased its survival to $28.5 \%$, a 3 -fold increase. Cotreatment with $1.5 \mathrm{mM} \mathrm{Mn}^{2+}$ and $10 \mathrm{mM} \mathrm{GSH}$ resulted in $74 \%$ survival, an 8.4-fold increase (Figure 3). It should be noted that 


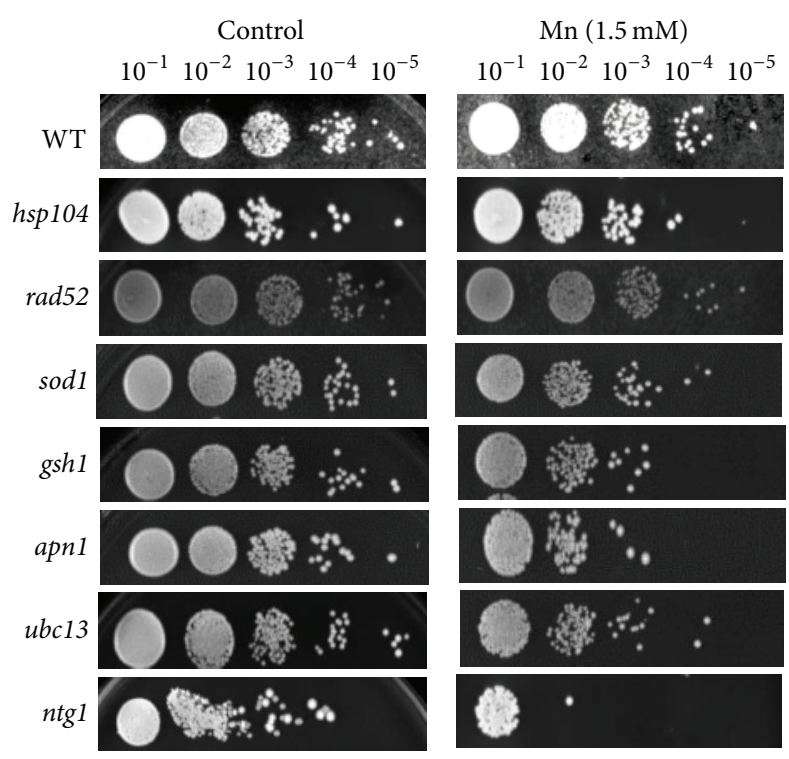

(a)

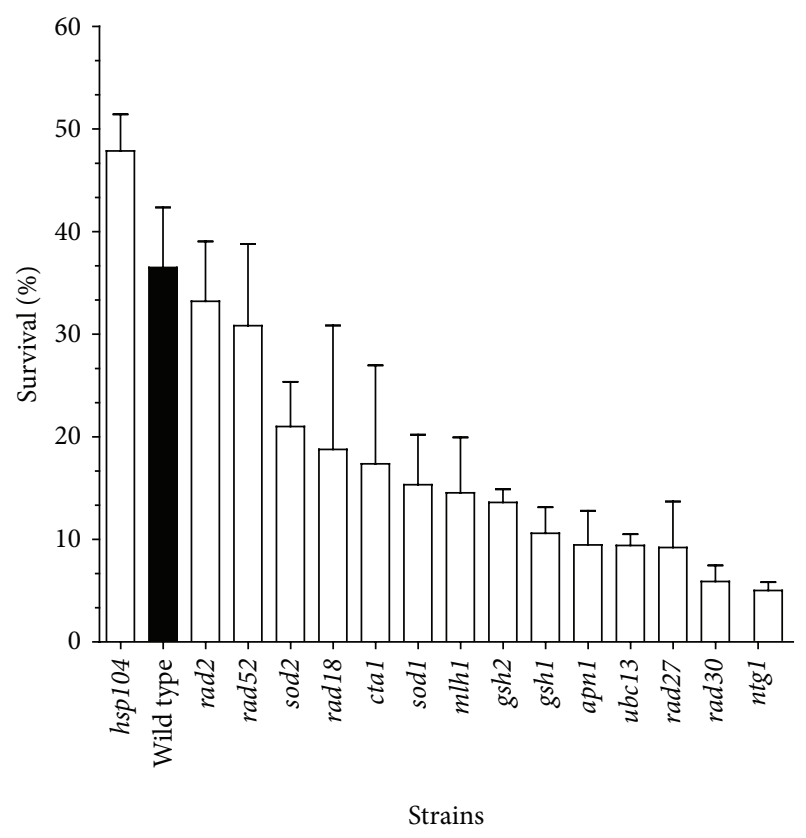

(b)

FIGURE 2: Sensitivity of yeast strains to $\mathrm{Mn}^{2+}$. (a) The survival of the strains in $1.5 \mathrm{mM} \mathrm{Mn}^{2+}$ was determined as described in Section 2 . Serial dilutions $\left(1: 10-1: 10^{5}\right)$ of treated cultures were spotted on YPD plates. Growth was scored after 3 days of incubation at $30^{\circ} \mathrm{C}$. The serial dilutions of the strains are shown. (b) Quantification of the survival of the tested strains. Survival was determined by counting the number of colonies in the respective dilutions and calculated based on the growth of strains not treated with $\mathrm{Mn}^{2+}$. Strains are presented as being ordered from least to more sensitive. Wild-type strain is depicted by a black bar.

cotreatment with either NAC or GSH alone did not have an effect on the growth of $u b c 13$ or wild-type strains.

\subsection{Analysis of the $\mathrm{Mn}^{2+}$-Induced Mutator Phenotype of Yeast.} The mutagenicity of $\mathrm{Mn}^{2+}$ has been extensively documented [19]. To determine the extent to which exposure to $\mathrm{Mn}^{2+}$ increases the accumulations of mutations and to quantify the increase in the mutation rate of wild-type yeast cells, we utilized the CAN1 forward mutation assay [33], as described in Section 2. As shown in Figure 4, the mutation rate increased 12-fold (from $1.9 \times 10^{-9}$ to $23.1 \times 10^{-7}$ ) when wildtype cells were treated with $1.5 \mathrm{mM} \mathrm{Mn}^{2+}$. Based on the ability of antioxidants to reduce the toxicity of $\mathrm{Mn}^{2+}$ (Figure 3), we tested if cotreatment with NAC or GSH could also reduce the $\mathrm{Mn}^{2+}$-induced increase of the mutation rate. In fact, $20 \mathrm{mM}$ $\mathrm{NAC}$ reduced the mutation rate by 1.5 -fold (from $23.1 \times 10^{-7}$ to $15.5 \times 10^{-7}$ ), while $10 \mathrm{mM} \mathrm{GSH}$ reduced the mutation rate by 2 -fold (from $23.1 \times 10^{-7}$ to $11.8 \times 10^{-7}$ ), consistent with the ability of these antioxidants to reduce Mn-induced toxicity (Figure 3).

3.4. Mutation Spectrum of CAN-Resistant Mutants. The CAN1 forward mutations assay provides a useful tool to identify the nature of the mutations that are generated from $\mathrm{Mn}^{2+}$ exposure. For this purpose, we amplified the CAN1 gene from canavanine-resistant colonies treated with $1.5 \mathrm{mM}$ $\mathrm{Mn}^{2+}$ and completely sequenced the ORF to identify the mutation. Table 2 shows the spectrum of mutations of 20 independent canavanine-resistant colonies. A single mutation was identified in each isolate. Mutations are indicated first by the original base, its numerical sequence position, followed by the mutant base. The majority $(70 \%)$ of the mutations were base-substitution mutations with $40 \%(8 / 20)$ being transitions and $30 \%$ transversions $(6 / 20)$. The rest (30\%) were frameshift mutations, of which $10 \%(2 / 20)$ were insertions and 20\% (4/20) were deletions of single nucleotides at the position indicated. No complex mutations such as large deletions, insertions, duplications, or gross chromosomal rearrangements were found. No hotspot was found, although some base-substitution mutations were observed twice (G1196A, G1555A and A1417T; Table 2).

3.5. $\mathrm{Mn}^{2+}$-Induced Reversion Mutations in the lys2-10A Allele Which Can Be Reduced by $\mathrm{Mg}^{2+}$. The $\mathrm{Mn}^{2+}$-induced accumulation of frameshift mutations prompted us to investigate if $\mathrm{Mn}^{2+}$ may be promoting polymerase slippage. For this purpose, we treated a yeast strain carrying the lys2-10A allele, where the LYS2 gene has a mononucleotide run of 10 adenines resulting in an out-of-frame gene, which can be restored by a frameshift mutation. We observed a dosedependent increase in the mutation rate of this strain with increasing concentrations of $\mathrm{Mn}^{2+}$ (Figure 5(a)). Even at low concentrations of $\mathrm{Mn}^{2+}(0.25 \mathrm{mM})$, the mutation rate increased by 13 -fold (from $2.1 \times 10^{-6}$ to $27.8 \times 10^{-6}$ ) and was 30 -fold $\left(2.1 \times 10^{-6}\right.$ to $\left.62.3 \times 10^{-6}\right)$ and 76 -fold $\left(2.1 \times 10^{-6}\right.$ to $160 \times 10^{-6}$ ) higher at $1.5 \mathrm{mM}$ and $3 \mathrm{mM}$ concentrations of $\mathrm{Mn}^{2+}$, respectively (Figure 5(a)). To determine if $\mathrm{Mn}^{2+}$ was 


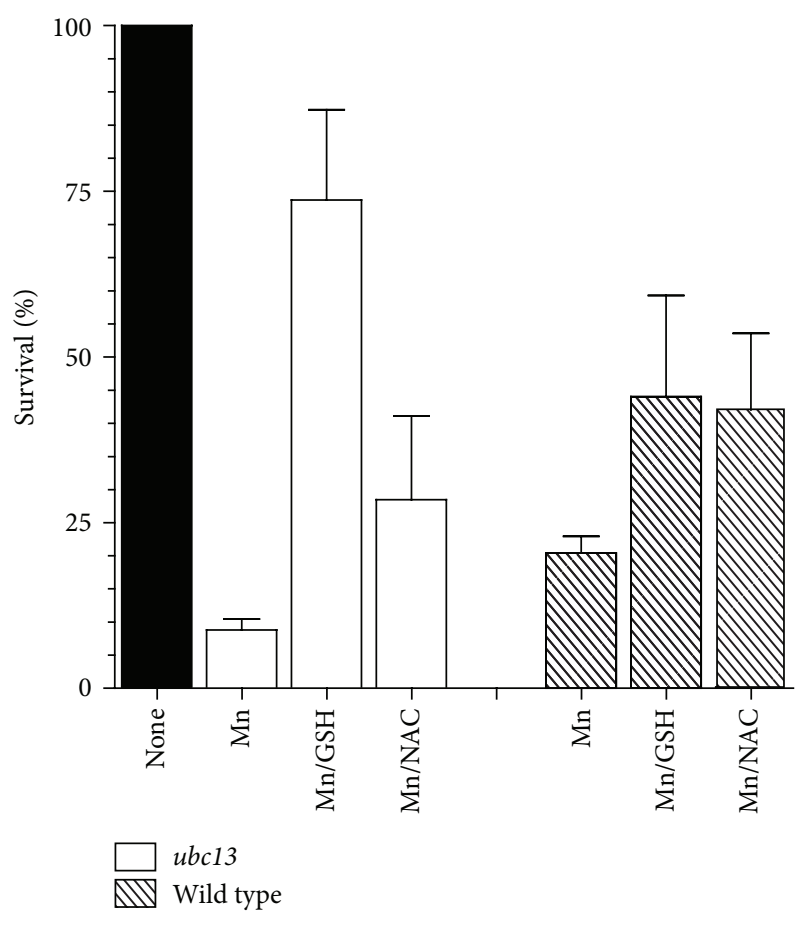

FIgURE 3: Attenuation of the cytotoxic effect of $\mathrm{Mn}^{2+}$ by exogenous antioxidants. Sensitive strain $u b c 13$ was treated with $1.5 \mathrm{mM} \mathrm{Mn}^{2+}$, $1.5 \mathrm{mM} \mathrm{Mn}^{2+}$ plus $10 \mathrm{mM}$ glutathione (GSH), and $1.5 \mathrm{mM} \mathrm{Mn}^{2+}$ plus $20 \mathrm{mM} \mathrm{N}$-acetylcysteine (NAC), as described in Section 2. Survival was determined relative to untreated strain (100\% survival). Wild-type strain was treated with $2 \mathrm{mM} \mathrm{Mn}^{2+}$, with or without cotreatment with GSH and NAC, as described in Section 2. At least 5 independent colonies were tested. Average survival plus standard deviation is shown.

TABLE 2: CAN1 mutation spectrum of wild-type yeast exposed to $\mathrm{Mn}^{2+}$.

Base substitution mutations

\begin{tabular}{lc} 
Transitions $(8 / 20)$ & Transversions $(6 / 20)$ \\
\hline G522A & A312T \\
G550A & A375C \\
C623T & T380G \\
G670A & A1417T $(\times 2)$ \\
G1196A $(\times 2)$ & A1645T \\
G1555A $(\times 2)$ & Frameshift mutations \\
\hline \multicolumn{3}{c}{ Insertions $(2 / 20)$} & Deletions $(4 / 20)$ \\
\hline & C417 \\
T740 & T1143 \\
T628 & G1259 \\
& G1474
\end{tabular}

displacing $\mathrm{Mg}^{2+}$ in the DNA synthesis reaction, we tested if exogenously added $\mathrm{Mg}^{2+}$ could both increase the survival of the strain as well as reduce its mutator phenotype. As shown in Figure 5(b), cotreatment of the strain with $1.5 \mathrm{mM} \mathrm{Mn}^{2+}$ and $10 \mathrm{mM} \mathrm{Mg}^{2+}$ significantly increased the survival to $100 \%$ (figure) and reduced the mutation rate by 2 -fold (Figure 5(c)).

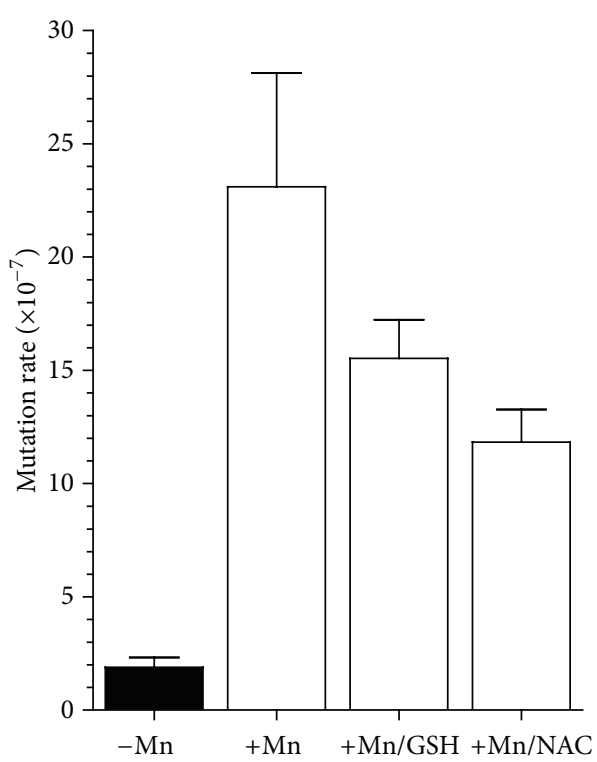

Figure 4: Effect of $\mathrm{Mn}^{2+}$ on the mutation rate of the CAN1 forward mutation assay. The CAN1 assay detects any mutation which inactivates the CAN1 gene (arginine permease) and allows cells to grow on plates containing the toxic arginine analog, canavanine. The assay was performed using the wild-type strain in the presence of $1.5 \mathrm{mM} \mathrm{Mn}^{2+}$ or cotreated with $1.5 \mathrm{mM} \mathrm{Mn}^{2+}$ and $10 \mathrm{mM} \mathrm{GSH}$ or $1.5 \mathrm{mM} \mathrm{Mn}^{2+}$ and $10 \mathrm{mM} \mathrm{NAC}$ as indicated. Appearance of colonies on canavanine containing plates is scored and mutation rates are determined as described in Section 2. and standard deviation is included at the top of each bar.

\section{Discussion}

Manganese is an essential trace metal required for normal physiological function. However, excess Mn exposure is associated with several disease states. Significant research focuses on chronic exposure to Mn which has been shown to cause manganism [10], a neurological disease referred to as idiopathic Parkinson's disease (IPD) that presents symptoms resembling the dystonic movement associated with Parkinson's disease (PD) [11-13]. Numerous studies suggest that the neurotoxicity as a result of $\mathrm{Mn}$ exposure is a consequence of a variety of factors including apoptosis, oxidative injury, DNA damage, mitochondrial dysfunction, and neuroinflammation [14-18]. Of particular interest is the mutagenicity of $\mathrm{Mn}$. Despite extensive knowledge of the DNA damaging properties of $\mathrm{Mn}$, little is known about the pathways involved in the response and repair of Mn-induced DNA damage.

In the present work, we investigate the contribution of various DNA repair pathways to the survival of yeast cells exposed to Mn toxicity. We selected mutant strains in key components of the major DNA repair pathways, as described in Table 2. Initial observation indicates that yeast cells are relatively tolerant to $\mathrm{Mn}^{2+}$, displaying reduced viability only when concentrations reach over $1 \mathrm{mM}$ (Figure 2), which is several orders of magnitude higher than for other metals, such as $\mathrm{Cd}^{2+}$, which is toxic at the $\mu \mathrm{M}$ level [31]. Interestingly, the sensitivity of yeast cells to $\mathrm{Mn}^{2+}$ is almost complete when 


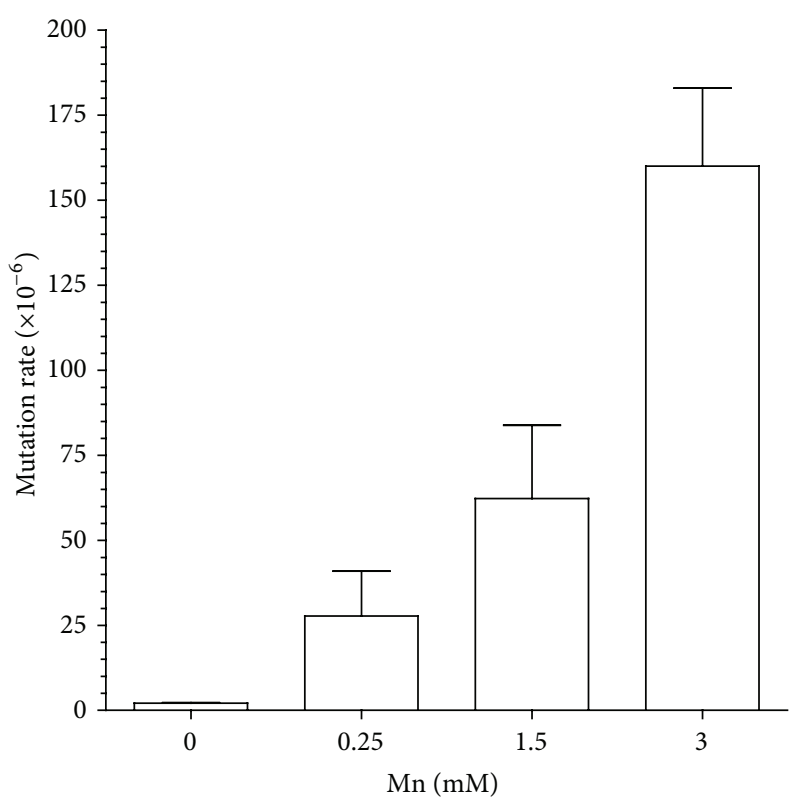

(a)

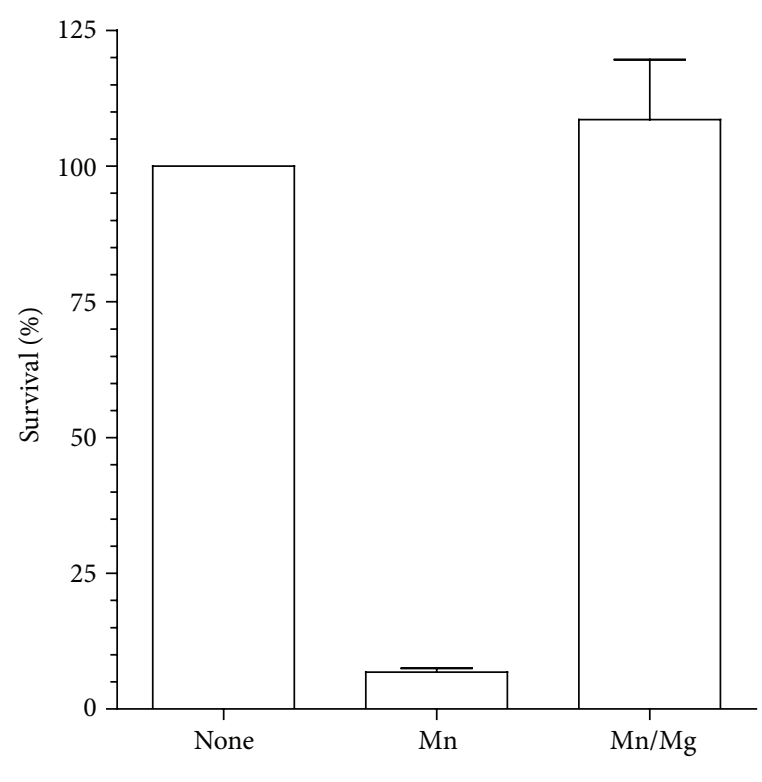

(b)

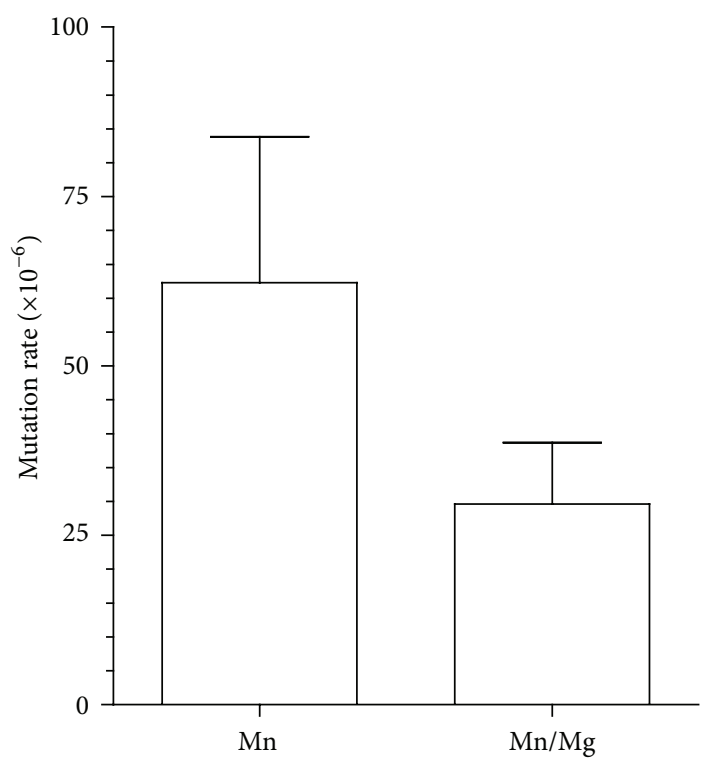

(c)

FIGURE 5: Effect of $\mathrm{Mn}^{2+}$ and $\mathrm{Mg}^{2+}$ on the mutation rate of the reversion of the lys2-10A allele. (a) Mutation rates determination by the yeast mutator assay using a strain carrying the lys2-10A allele was performed in the presence of increasing concentrations of $\mathrm{Mn}^{2+}$. The appearance of Lys ${ }^{+}$revertant colonies indicates a mutator phenotype. Rates are calculated as described in Section 2 and standard deviation is included at the top of each bar. (b) Cotreatment with $10 \mathrm{mM} \mathrm{Mg}{ }^{2+}$ protects cells from the toxicity of $\mathrm{Mn}^{2+}$. Survival was determined as described in Section 2. (c) Cotreatment with $10 \mathrm{mM} \mathrm{Mg}^{2+}$ reduces the accumulation of mutations on the lys $2-10 \mathrm{~A}$ allele induced by $1.5 \mathrm{mM} \mathrm{Mn}{ }^{2+}$. Each bar corresponds to the average of three sets of experiments using five independent colonies per set.

the concentration of $\mathrm{Mn}^{2+}$ reaches $2.5 \mathrm{mM}$ (Figure 2) displaying a linear response within this concentration window. For this reason, the strain comparison was performed at the $1.5 \mathrm{mM}$ concentration. All strains displayed varying degrees of sensitivity, and all except the hsp104 strain, were more sensitive than the wild type, suggesting that no significant toxic levels of protein aggregation are induced by $\mathrm{Mn}^{2+}$.
Cells possess three major excision repair pathways: (i) base excision repair (BER) which is responsible for the repair of damaged bases resulting primarily from oxidative damage [34], (ii) nucleotide excision repair (NER) which plays a major role in the repair of large DNA adducts and UV damaged DNA [35, 36], and (iii) DNA mismatch repair (MMR), a postreplicative mechanism, improves the fidelity 
of DNA replication by removing misincorporated bases by the DNA polymerase [37]. In addition, cells possess recombination repair, which in yeast is primarily performed by homologous recombination (HR) [38]. These pathways act in concert to respond to exogenous damage and guarantee genome stability. Some of these pathways have been shown to be defective in neurodegenerative diseases $[39,40]$ and participate in response to neurotoxic agents [41, 42]. Our data suggests that BER plays a major role in the cellular response to toxic levels of $\mathrm{Mn}^{2+}$ as mutants apn1, rad27, and ntg1 were more than 4-fold sensitive to $\mathrm{Mn}^{2+}$ than wild type (Figure 2(b)) and ntg1 was the most sensitive (7.5-fold). NTG1 is a DNA N-glycosylase which removes the oxidized damaged base on both nuclear and mitochondrial DNA [43]. The DNA damage generated by $\mathrm{Mn}^{2+}$ appears to interfere with DNA replication, as indicated by the high sensitivity of strains $u b c 13$, a DNA-damage-inducible gene, member of the errorfree postreplication repair pathway [44], and rad30 mutants, which are defective in translesion synthesis DNA polymerase eta, required for bypass synthesis at sites where replication forks are stalled due to damaged bases. Conversely, NER does not appear to play a major role in the repair of $\mathrm{Mn}^{2+}$-induced DNA damage, as indicated by similar survival of rad 2 mutant to the wild type. Similarly, the lack of a strong $\mathrm{Mn}^{2+}$-induced phenotype in the rad52 strain suggests that no significant DNA damage is processed to DNA double-strand breaks, which requires homologous recombination for repair.

It appears that oxidative stress plays a major role in $\mathrm{Mn}^{2+}$ cytotoxicity as indicated by the increased sensitivity of the superoxide dismutase ( $\operatorname{sod} 1$ and $\operatorname{sod} 2)$ and catalase mutants (ctal). This is further supported by the ability of NAC to improve the survival of the wild-type strain and the DNA repair strain $u b c 13$ (Figure 3). Exogenous addition of glutathione, which serves both as a reducing agent and a chelator to $\mathrm{Mn}$, further protected the strains from $\mathrm{Mn}^{2+}$ exposure.

A significant increase in the accumulation of mutations was observed in cells exposed to $\mathrm{Mn}^{2+}$, using two distinct mutator assays. The CAN1 forward mutation assay indicated a 12 -fold increase in the mutation rate when cells were exposed to $1.5 \mathrm{mM} \mathrm{Mn}^{2+}$. Similar to the effect on survival, NAC and GSH reduced the increase in the mutation rate, suggesting that the mutations are at least the result of oxidative damage to DNA. Analysis of the mutations in the CAN1 gene in these yeast cells indicates that most base substitutions are accumulated (70\%), while 30\% were frameshifts mutations. In combination with the increased mutation rate, cells exposed to $\mathrm{Mn}^{2+}$ have a significantly higher accumulation of frame shift mutations. This is distinct from spontaneous mutations (not exposed to $\mathrm{Mn}^{2+}$ ), where $10 \%$ of the mutants analyzed had complex mutations $[29,45]$. The increase in frameshift mutations was also observed when the mutation rate was measured using the lys2-10A allele. This increase was dosedependent and ameliorated by $\mathrm{Mg}^{2+}$, concomitant with an increase in cell survival. In fact, $\mathrm{Mg}^{2+}$ has been shown to protect cells from $\mathrm{Mn}^{2+}$ toxicity [46-48]. It is possible that the mutation rate increase is the result of $\mathrm{Mn}^{2+}$ intoxication of the DNA polymerase by displacing $\mathrm{Mg}^{2+}[21]$, which would require MMR for repair, explaining the increased sensitivity of the mlh1 strain.

The adverse effect of $\mathrm{Mn}^{2+}$ in DNA polymerase fidelity has been previously reported [21] and proposed to be due to replacement of $\mathrm{Mg}^{2+}$, which is essential in the reaction. However, recently, a series of studies have shown that some viral polymerases, such as those of coronavirus [49] and poliovirus [50], have exclusive requirement for $\mathrm{Mn}^{+2}$ in their synthetic activity. Similarly, the incorporation of nonnucleoside triphosphate analogs is accomplished by $\mathrm{X}$ family DNA polymerases in an Mn-dependent manner [51], while cellular error-prone DNA polymerase iota, isolated from tumor cells, was shown to utilize $\mathrm{Mn}^{2+}$ [52] in DNA synthesis. This is an interesting observation because DNA polymerase iota is inducible by $\mathrm{Mn}^{2+}$ and could in part contribute to the mutagenesis observed in $\mathrm{Mn}^{2+}$ exposed cells.

Most published work on the toxicity of manganese has focused on $\mathrm{Mn}^{2+}$, while there was some claim that $\mathrm{Mn}^{3+}$ was the toxic species. However, recent work indicates that $\mathrm{Mn}^{3+}$ has a significantly reduced toxicity compared to $\mathrm{Mn}^{2+}$ $[53,54]$. In addition, since manganese has a similar ionic radius to calcium, $\mathrm{Mn}^{2+}$ has been shown to interfere with $\mathrm{Ca}^{2+}$ metabolism $[19,55]$. However, there are no reports of $\mathrm{Ca}^{2+}$ having an effect on BER.

The data presented in this study indicates that $\mathrm{Mn}^{2+}$ induced DNA damage is in part due to oxidative stress and requires base excision repair. Considering the well-known relationship between DNA repair defects and neurodegenerative diseases, and the involvement of DNA repair in response to neurotoxic agents, the status of base excision repair, or some of its key components, may prove to be useful as biomarkers to determine the susceptibility to toxic damage from excess exposure to $\mathrm{Mn}^{2+}$. There is currently a lack of well-validated biomarkers for manganese exposure. Manganese overexposure leads to cognitive, motor, behavioral effects in children [56] and manganese is associated with Parkinson's disease in adults [11-13]. Persons most likely to be exposed to excessive levels of manganese are manganese coal miners and welders. However, there is currently no way to determine who will suffer severe effects after Mn overexposure. Thus, preventive strategies and biomarker development for BER status are strongly supported by our findings. An assay that monitors the BER status of exposed individuals could be used in conjunction with other recently proposed biomarkers for $\mathrm{Mn}$ exposure which measure delta-amino levulinic acid levels [57] and the $\mathrm{Mn} / \mathrm{Fe}$ ratio [58]. While these two biomarkers can detect exposure to $\mathrm{Mn}$, an assay evaluating BER status would be of more value as a preventative strategy with its inherent potential to distinguish individuals who would be more severely affected by $\mathrm{Mn}$ exposure from those who would not.

\section{Authors' Contribution}

Adrienne P. Stephenson and Tryphon K. Mazu shared equally in this work. 


\section{Acknowledgments}

The authors are grateful for the support provided by the Gene and Cell Manipulation Facility of Florida A\&M University. This project was supported by the National Center for Research Resources and the National Institute of Minority Health and Health Disparities of the National Institutes of Health through Grant nos. 2 G12 RR003020 and 8 G12 MD007582-28. They appreciate the support from the following funding agencies: Association of Minority Health Professions Schools, Inc. (AMPHS) and the ATS/DR Cooperative Agreement no. 3U50TS473408-05W1/CFDA and no. 93.161 (RRR) NIEHS/ARCH 5S11ES01187-05 (RRR).

\section{References}

[1] J. R. Prohaska, "Functions of trace elements in brain metabolism," Physiological Reviews, vol. 67, no. 3, pp. 858901, 1987.

[2] L. S. Hurley, "The roles of trace elements in foetal and neonatal development," Philosophical Transactions of the Royal Society B, vol. 294, pp. 145-152, 1981.

[3] L. S. Hurley, C. L. Keen, and D. L. Baly, "Manganese deficiency and toxicity: effects on carbohydrate metabolism in the rat," NeuroToxicology, vol. 5, no. 1, pp. 97-104, 1984.

[4] F. C. Wedler, "3 Biological significance of manganese in mammalian systems," Progress in Medicinal Chemistry, vol. 30, pp. 89-133, 1993.

[5] US Environmental Protection Agency, "National Center for Environmental Assessment," 1999.

[6] US Department of Health and Human Services, Toxicological Profile for Manganese, The Agency for Toxic Substances and Disease Registry, Ed., US Department of Health and Human Services, Atlanta, Ga, USA, 1992.

[7] L. E. Gray Jr. and J. W. Laskey, "Multivariate analysis of the effects of manganese on the reproductive physiology and behavior of the male house mouse," Journal of Toxicology and Environmental Health, vol. 6, no. 4, pp. 861-867, 1980.

[8] D. Mergler and M. Baldwin, "Early manifestations of manganese neurotoxicity in humans: an update," Environmental Research, vol. 73, no. 1-2, pp. 92-100, 1997.

[9] A. Wennberg, A. Iregren, G. Struwe, G. Cizinsky, M. Hagman, and L. Johansson, "Manganese exposure in steel smelters a health hazard to the nervous system," Scandinavian Journal of Work, Environment and Health, vol. 17, no. 4, pp. 255-262, 1991.

[10] M. Aschner and D. C. Dorman, "Manganese: pharmacokinetics and molecular mechanisms of brain uptake," Toxicological Reviews, vol. 25, no. 3, pp. 147-154, 2006.

[11] T. R. Guilarte, "Manganese and Parkinson's disease: a critical review and new findings," Environmental Health Perspectives, vol. 118, no. 8, pp. 1071-1080, 2010.

[12] D. B. Calne, N.-S. Chu, C.-C. Huang, C.-S. Lu, and W. Olanow, "Manganism and idiopathic parkinsonism: similarities and differences," Neurology, vol. 44, no. 9, pp. 1583-1586, 1994.

[13] L. Normandin and A. S. Hazell, "Manganese neurotoxicity: an update of pathophysiologic mechanisms," Metabolic Brain Disease, vol. 17, no. 4, pp. 375-387, 2002.

[14] D. L. Stredrick, A. H. Stokes, T. J. Worst et al., "Manganeseinduced cytotoxicity in dopamine-producing cells," NeuroToxicology, vol. 25, no. 4, pp. 543-553, 2004.
[15] C.-J. Chen and S.-L. Liao, "Oxidative stress involves in astrocytic alterations induced by manganese," Experimental Neurology, vol. 175, no. 1, pp. 216-225, 2002.

[16] K. Seth, A. K. Agrawal, I. Date, and P. K. Seth, "The role of dopamine in manganese-induced oxidative injury in rat pheochromocytoma cells," Human and Experimental Toxicology, vol. 21, no. 3, pp. 165-170, 2002.

[17] C. G. Worley, D. Bombick, J. W. Allen, R. Lee Suber, and M. Aschner, "Effects of manganese on oxidative stress in CATH.a cells," NeuroToxicology, vol. 23, no. 2, pp. 159-164, 2002.

[18] A. P. Stephenson, J. A. Schneider, B. C. Nelson et al., "Manganese-induced oxidative DNA damage in neuronal SHSY5Y cells: attenuation of thymine base lesions by glutathione and N-acetylcysteine," Toxicology Letters, vol. 218, pp. 299-307, 2013.

[19] G. B. Gerber, A. Léonard, and P. Hantson, "Carcinogenicity, mutagenicity and teratogenicity of manganese compounds," Critical Reviews in Oncology/Hematology, vol. 42, no. 1, pp. 2534, 2002.

[20] M. de Meo, M. Laget, M. Castegnaro, and G. Dumenil, "Genotoxic activity of potassium permenganate in acidic solutions," Mutation Research, vol. 260, no. 3, pp. 295-306, 1991.

[21] R. A. Beckman, A. S. Mildvan, and L. A. Loeb, "On the fidelity of DNA replication: manganese mutagenesis in vitro," Biochemistry, vol. 24, no. 21, pp. 5810-5817, 1985.

[22] P. Olivier and D. Marzin, "Study of the genotoxic potential of 48 inorganic derivatives with the SOS chromotest," Mutation Research/Genetic Toxicology, vol. 189, no. 3, pp. 263-269, 1987.

[23] A. Orgel and L. E. Orgel, "Induction of mutations in bacteriophage T4 with divalent manganese," Journal of Molecular Biology, vol. 14, no. 2, pp. 453-457, 1965.

[24] A. Putrament, H. Baranowska, and W. Prazmo, "Induction by manganese of mitochondrial antibiotic resistance mutations in yeast," Molecular and General Genetics, vol. 126, no. 4, pp. 357366, 1973.

[25] W. Prazmo, E. Balbin, and H. Baranowska, "Manganese mutagenesis in yeast. II. Conditions of induction and characteristics of mitochondrial respiratory deficient Saccharomyces cerevisiae mutants induced with manganese and cobalt," Genetical Research, vol. 26, no. 1, pp. 21-29, 1975.

[26] J. Bornhorst, F. Ebert, A. Hartwig, B. Michalke, and T. Schwerdtle, "Manganese inhibits poly(ADP-ribosyl)ation in human cells: a possible mechanism behind manganese-induced toxicity?" Journal of Environmental Monitoring, vol. 12, no. 11, pp. 2062-2069, 2010.

[27] D. R. Marzin and H. V. Phi, "Study of the mutagenicity of metal derivatives with Salmonella typhimurium TA102," Mutation Research, vol. 155, no. 1-2, pp. 49-51, 1985.

[28] E. Alani, R. A. G. Reenan, and R. D. Kolodner, "Interaction between mismatch repair and genetic recombination in Saccharomyces cerevisiae," Genetics, vol. 137, no. 1, pp. 19-39, 1994.

[29] D. X. Tishkoff, N. Filosi, G. M. Gaida, and R. D. Kolodner, "A novel mutation avoidance mechanism dependent on $\mathrm{S}$. cerevisiae RAD27 is distinct from DNA mismatch repair," Cell, vol. 88, no. 2, pp. 253-263, 1997.

[30] H. Flores-Rozas and R. D. Kolodner, “The Saccharomyces cerevisiae MLH3 gene functions in MSH3-dependent suppression of frameshift mutations," Proceedings of the National Academy of Sciences of the United States of America, vol. 95, no. 21, pp. 12404-12409, 1998. 
[31] S. Banerjee and H. Flores-Rozas, "Cadmium inhibits mismatch repair by blocking the ATPase activity of the MSH2-MSH6 complex," Nucleic Acids Research, vol. 33, no. 4, pp. 1410-1419, 2005.

[32] G. T. Marsischky, N. Filosi, M. F. Kane, and R. Kolodner, "Redundancy of Saccharomyces cerevisiae MSH3 and MSH6 in MSH2-dependent mismatch repair," Genes and Development, vol. 10, no. 4, pp. 407-420, 1996.

[33] K. Ekwall and T. Ruusala, "Budding yeast CAN1 gene as a selection marker in fission yeast," Nucleic Acids Research, vol. 19, no. 5, p. 1150, 1991.

[34] G. L. Dianov and U. Hubscher, "Mammalian base excision repair: the forgotten archangel," Nucleic Acids Research, vol. 41, pp. 3483-3490, 2013.

[35] K. Diderich, M. Alanazi, and J. H. J. Hoeijmakers, "Premature aging and cancer in nucleotide excision repair-disorders," DNA Repair, vol. 10, no. 7, pp. 772-780, 2011.

[36] K. Sugasawa, "Regulation of damage recognition in mammalian global genomic nucleotide excision repair," Mutation Research, vol. 685, no. 1-2, pp. 29-37, 2010.

[37] B. D. Preston, T. M. Albertson, and A. J. Herr, "DNA replication fidelity and cancer," Seminars in Cancer Biology, vol. 20, no. 5, pp. 281-293, 2010.

[38] R. Amunugama and R. Fishel, "Homologous recombination in eukaryotes," Progress in Molecular Biology and Translational Science, vol. 110, pp. 155-206, 2012.

[39] J. J. Reynolds and G. S. Stewart, "A single strand that links multiple neuropathologies in human disease," Brain, vol. 136, pp. 14-27, 2013.

[40] D. K. Jeppesen, V. A. Bohr, and T. Stevnsner, "DNA repair deficiency in neurodegeneration," Progress in Neurobiology, vol. 94, no. 2, pp. 166-200, 2011.

[41] I. I. Kruman, G. I. Henderson, and S. E. Bergeson, "DNA damage and neurotoxicity of chronic alcohol abuse," Experimental Biology and Medicine, vol. 237, pp. 740-747, 2012.

[42] K. Doi, "Mechanisms of neurotoxicity induced in the developing brain of mice and rats by DNA-damaging chemicals," Journal of Toxicological Sciences, vol. 36, no. 6, pp. 695-712, 2011.

[43] I. Alseth, L. Eide, M. Pirovano, T. Rognes, E. Seeberg, and M. Bjørås, "The Saccharomyces cerevisiae homologues of endonuclease III from Escherichia coli, Ntg1 and Ntg2, are both required for efficient repair of spontaneous and induced oxidative DNA damage in yeast," Molecular and Cellular Biology, vol. 19, no. 5, pp. 3779-3787, 1999.

[44] J. Brusky, Y. Zhu, and W. Xiao, "UBC13, a DNA-damageinducible gene, is a member of the error-free postreplication repair pathway in Saccharomyces cerevisiae," Current Genetics, vol. 37, no. 3, pp. 168-174, 2000.

[45] P. J. Lau, H. Flores-Rozas, and R. D. Kolodner, "Isolation and characterization of new proliferating cell nuclear antigen (POL30) mutator mutants that are defective in DNA mismatch repair," Molecular and Cellular Biology, vol. 22, no. 19, pp. 66696680, 2002.

[46] K. J. Blackwell, J. M. Tobin, and S. V. Avery, "Manganese uptake and toxicity in magnesium supplemented and unsupplemented Saccharomyces cerevisiae," Applied Microbiology and Biotechnology, vol. 47, no. 2, pp. 180-184, 1997.

[47] R. Malcová, M. Gryndler, and M. Vosátka, "Magnesium ions alleviate the negative effect of manganese on Glomus claroideum BEG23," Mycorrhiza, vol. 12, no. 3, pp. 125-129, 2002.
[48] A. Peters, S. Lofts, G. Merrington, B. Brown, W. Stubblefield, and K. Harlow, "Development of biotic ligand models for chronic manganese toxicity to fish, invertebrates, and algae," Environmental Toxicology and Chemistry, vol. 30, no. 11, pp. 2407-2415, 2011.

[49] D. G. Ahn, J. K. Choi, D. R. Taylor, and J. W. Oh, "Biochemical characterization of a recombinant SARS coronavirus nsp12 RNA-dependent RNA polymerase capable of copying viral RNA templates," Archives of Virology, vol. 157, pp. 2095-2104, 2012.

[50] S. Crotty, D. Gohara, D. K. Gilligan, S. Karelsky, C. E. Cameron, and R. Andino, "Manganese-dependent polioviruses caused by mutations within the viral polymerase," Journal of Virology, vol. 77, no. 9, pp. 5378-5388, 2003.

[51] E. Crespan, S. Zanoli, A. Khandazhinskaya et al., "Incorporation of non-nucleoside triphosphate analogues opposite to an abasic site by human DNA polymerases $\beta$ and $\lambda$," Nucleic Acids Research, vol. 33, no. 13, pp. 4117-4127, 2005.

[52] A. V. Lakhin, A. S. Efremova, I. V. Makarova et al., "Effect of $\mathrm{Mn}(\mathrm{II})$ on the error-prone DNA polymerase iota activity in extracts from human normal and tumor cells," Molecular Genetics, Microbiology and Virology, vol. 28, no. 1, pp. 1-7, 2013.

[53] P. Huang, G. Li, C. Chen et al., "Differential toxicity of $\mathrm{Mn}^{2+}$ and $\mathrm{Mn}^{3+}$ to rat liver tissues: oxidative damage, membrane fluidity and histopathological changes," Experimental and Toxicologic Pathology, vol. 64, no. 3, pp. 197-203, 2012.

[54] T. E. Gunter, C. E. Gavin, M. Aschner, and K. K. Gunter, "Speciation of manganese in cells and mitochondria: a search for the proximal cause of manganese neurotoxicity," NeuroToxicology, vol. 27, no. 5, pp. 765-776, 2006.

[55] A. Pinsino, M. C. Roccheri, C. Costa, and V. Matranga, "Manganese interferes with calcium, perturbs ERK signaling, and produces embryos with no skeleton," Toxicological Sciences, vol. 123, no. 1, pp. 217-230, 2011.

[56] S. Zoni and R. G. Lucchini, "Manganese exposure: cognitive, motor and behavioral effects on children: a review of recent findings," Current Opinion in Pediatrics, vol. 25, pp. 255-260, 2013.

[57] V. Andrade, M. L. Mateus, M. C. Batoreu, M. Aschner, and A. P. Dos Santos, "Urinary delta-ALA: a potential biomarker of exposure and neurotoxic effect in rats co-treated with a mixture of lead, arsenic and manganese," Neurotoxicology, vol. 38, pp. 33-41, 2013.

[58] W. Zheng, S. X. Fu, U. Dydak, and D. M. Cowan, "Biomarkers of manganese intoxication," NeuroToxicology, vol. 32, no. 1, pp. $1-8,2011$. 

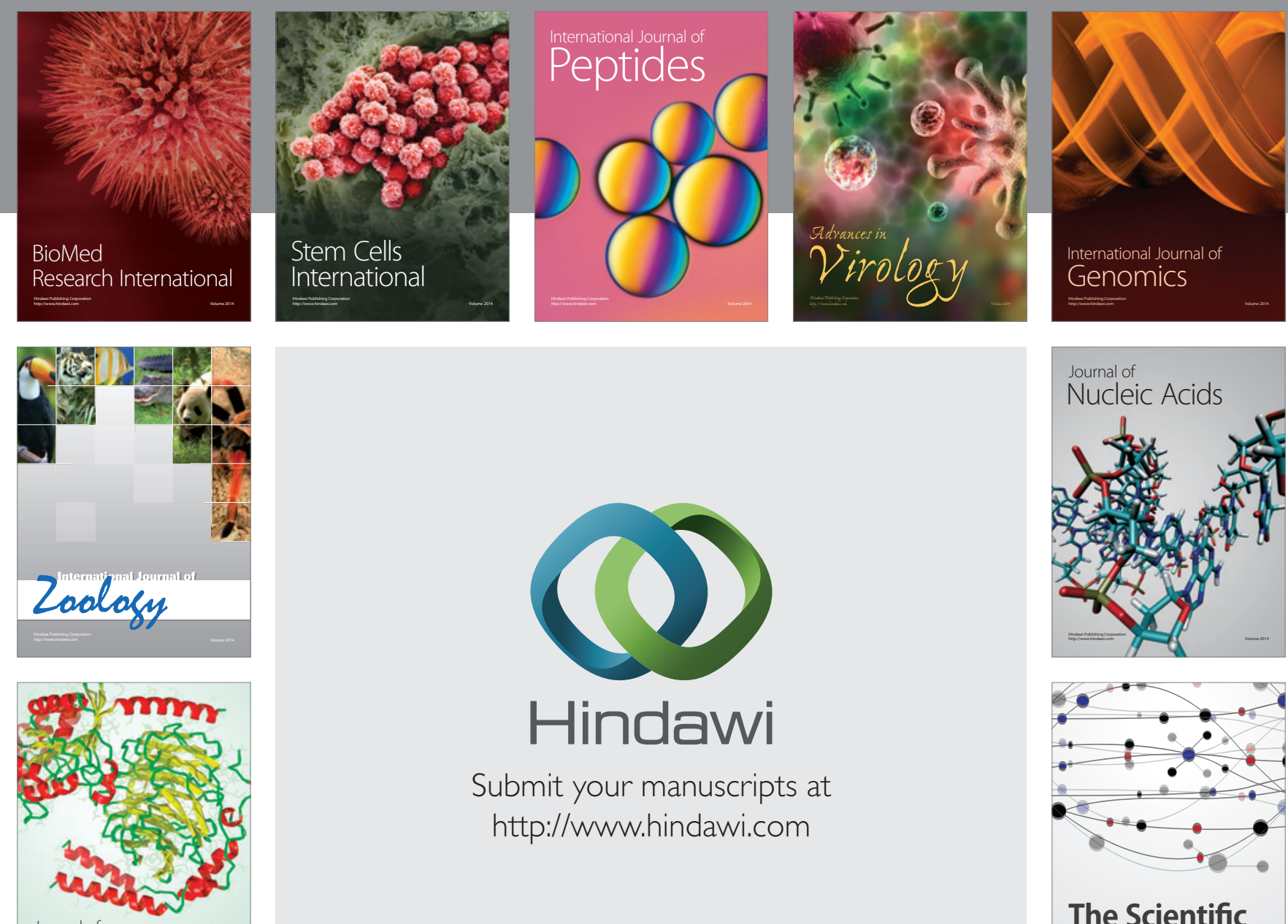

Submit your manuscripts at

http://www.hindawi.com

Journal of
Signal Transduction
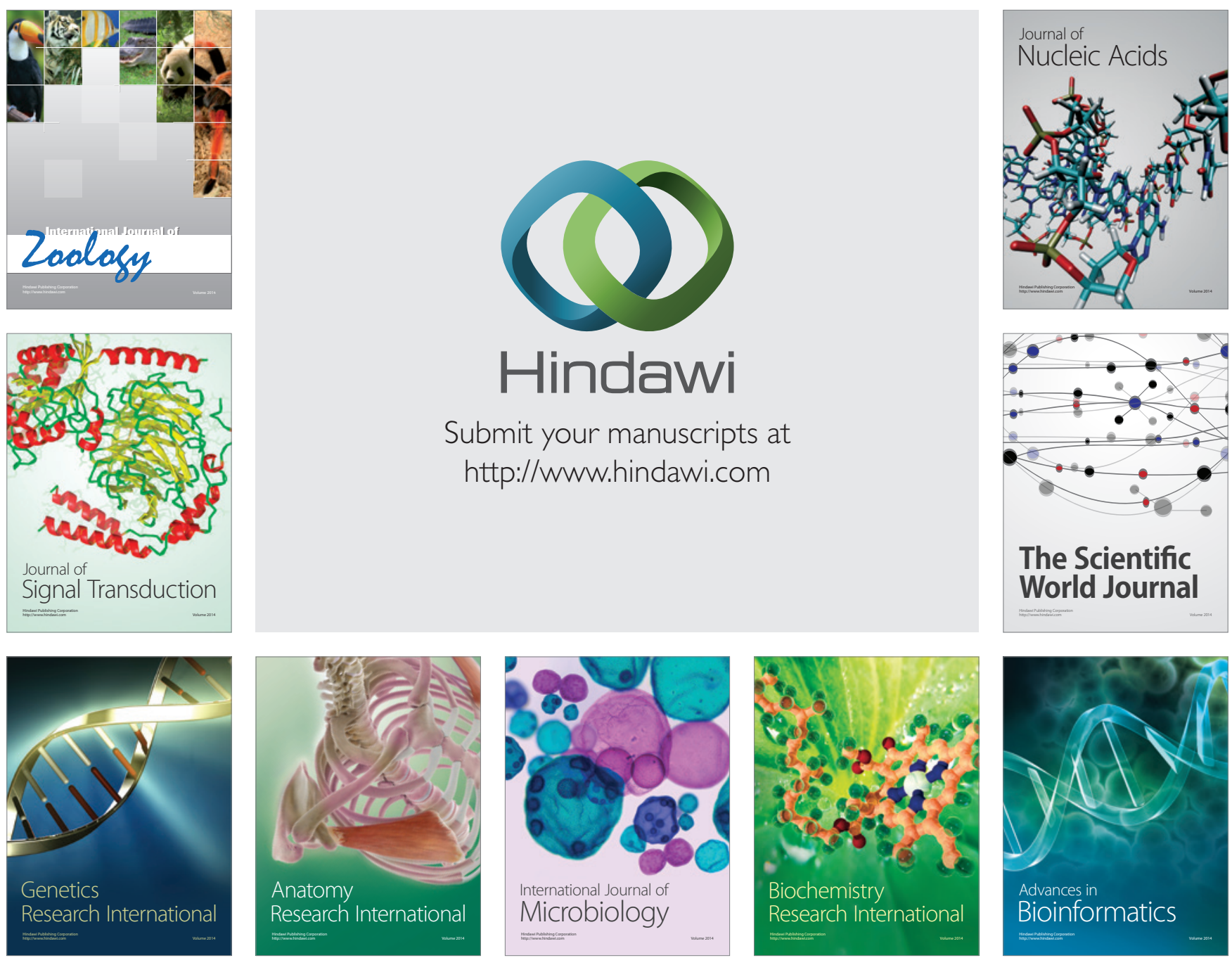

The Scientific World Journal
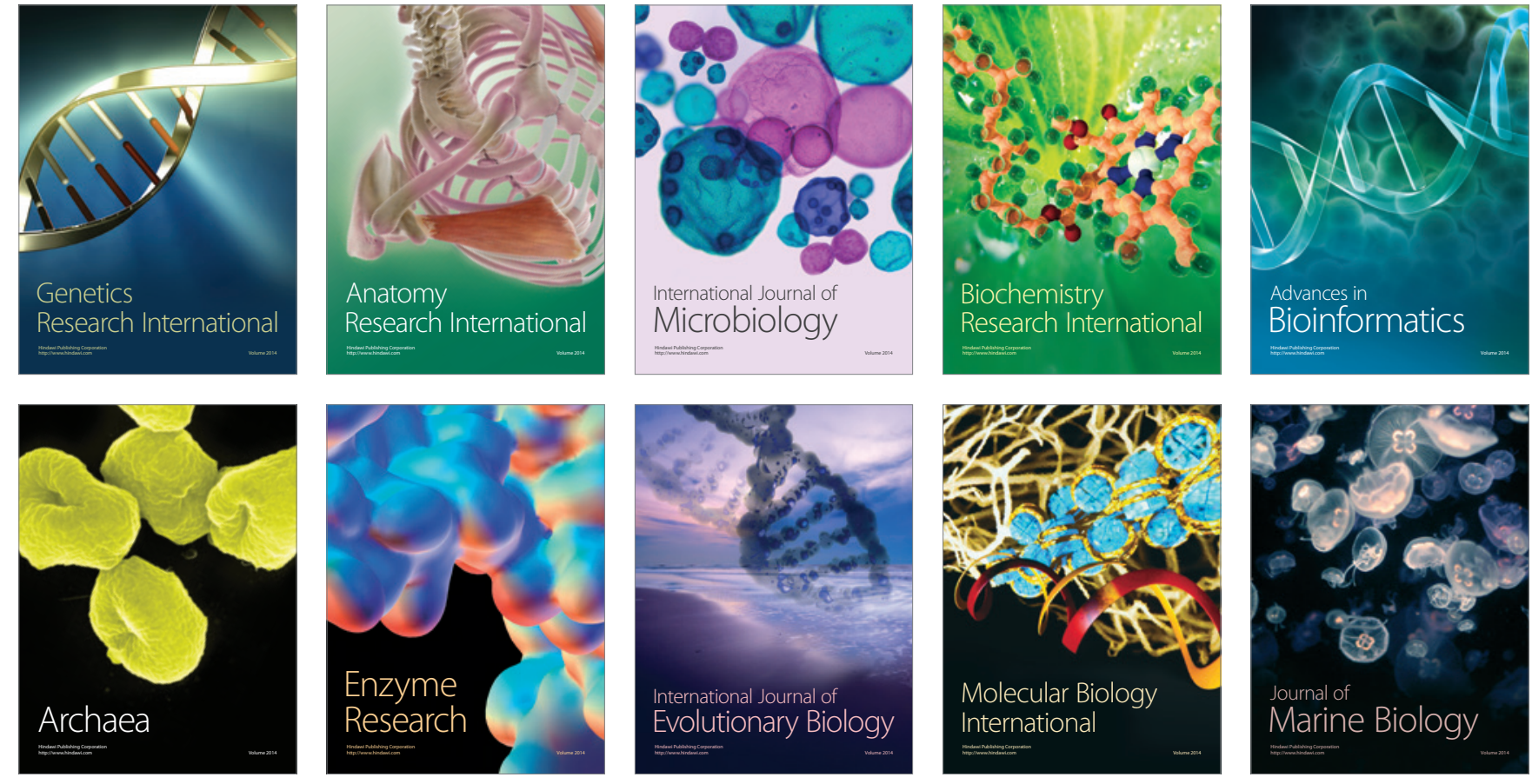